\title{
Indolent Adult Non-Hodgkin Lymphoma
}

National Cancer Institute

\section{Source}

National Cancer Institute. Indolent Adult Non-Hodgkin Lymphoma. NCI Thesaurus. Code C8491.

An indolent non-Hodgkin lymphoma occurring in adults. Representative examples include small lymphocytic lymphoma, lymphoplasmacytic lymphoma/Waldenstrom's macroglobulinemia, marginal zone B-cell lymphoma, and grade 1 and 2 follicular lymphoma. 